Article

\title{
Performance Degradation of Large-Sized Asphalt Mixture Specimen under Heavy Load and Its Affecting Factors Using Multifunctional Pavement Material Tester
}

\author{
Jiasheng Li ${ }^{1}$, Jianying $\mathrm{Yu}^{1}$, Jun Xie ${ }^{1, *}$ and Qunshan $\mathrm{Ye}^{2}$ \\ 1 State Key Laboratory of Silicate Materials of Architectures, Wuhan University of Technology, \\ Wuhan 430070, China; lijiasheng@whut.edu.cn (J.L.); jyyu@whut.edu.cn (J.Y.) \\ 2 Key Laboratory of Road Structure and Material of Ministry of Transport (Changsha), Changsha University of \\ Science \& Technology, Changsha 410114, China; yeqs@whut.edu.cn \\ * Correspondence: xiejun3970@whut.edu.cn
}

Received: 15 October 2019; Accepted: 18 November 2019; Published: 20 November 2019

\begin{abstract}
With the increase of heavy traffic transportation, it is meaningful to study the performance change of pavements under heavy loads. To study the development of asphalt mixture under heavy load, an AC-13 asphalt mixture was prepared and a large-sized specimen wheel tracking test was conducted. Samples from different periods were extracted to research the influence of the cumulative load times under heavy load on asphalt mixtures. It was found that there were different variation rules on the performance of the asphalt mixture under different load conditions. The failure time on skid resistance was predicted by the fitting curve. Heavy load conditions would greatly speed up the failure of skid resistance. According to the sieving results, the stable gradation of 10-16 mm, 5-10 $\mathrm{mm}, 3-5 \mathrm{~mm}$, and 0-3 $\mathrm{mm}$ after heavy load grinding was $10 \%, 37 \%, 23 \%$, and $30 \%$. It was found that the content of 10-16 $\mathrm{mm}$ had a significant correlation with the permanent deformation of the asphalt mixture, while there were no significant correlation between aggregate and skid resistance.
\end{abstract}

Keywords: asphalt mixture; heavy load; permanent deformation; skid resistance; aggregate sieving

\section{Introduction}

With the development of road transport, the highway sustains enormous traffic volume, especially with many overloaded trucks. The wheel rolling action of overloaded trucks' is one of the major causes of permanent deformation and a reduction of pavement performance of asphalt mixture surface layer [1,2]. Heavy loads increase the contact and resistance between the tire and the ground, which accelerate the polishing effect of pavement surface, resulting in the decline of the skid resistance of the asphalt mixture and increasing the risk for traffic safety [3,4].

Driven by economic interests and other factors, the heavy trucks on the highway are overloaded frequently in China. At present, the average axle load of heavy vehicles is about 12-18 $\mathrm{t}$ in China, and the tire pressure is about 0.8-1.1 MPa. With different tire pressure, tread pattern, and load, the effective grounding area of the tire is about $25,000-70,000 \mathrm{~mm}^{2}$. The replacement diameter of wheels is about $175-300 \mathrm{~mm}$. The actual axle load of trucks takes 50\%-100\% more than rated in general and the pressure could be up to $1.7 \mathrm{MPa}$, which has brought serious impact on the road pavement [5]. Normally, the newly built pavement can easily meet the requirements of strength and skid resistance. However, with the compacting, wearing, and polishing of the vehicle, many pavements lose their stable structure, followed by a rapid decrease in their strength and anti-skid ability [6]. 
Permanent deformation directly reflects the riding comfort and safety and service life of an asphalt pavement [4]. Texture depth (TD) and British pendulum number (BPN) can reflect the surface texture and skid resistance of the pavement indirectly [7,8]. Normally, asphalt pavements with higher TD and lower BPN have superior skid resistance $[9,10]$. The test of TD and BPN can compendiously describe the macro texture depth and friction coefficient, respectively [11]. These brief measurement methods will provide significant information for policymakers to optimize pavements [12,13].

The majority of studies on the performance of the asphalt mixture has focused on the selection of aggregates and the gradation of mixture, while there has been relatively few research on the influence of heavy load $[7,14,15]$. Considering the characteristic of heavy axle load in modern transportation, the objective of this study was to measure the mechanics and skid resistance after various heavy loads on asphalt concrete (AC) pavements. The mechanical performance was measured by permanent deformation and the skid resistance was measured by TD and BPN through the sand patch method and British pendulum. Furthermore, the aggregate gradation after heavy load was analyzed.

\section{Materials and Experimental Program}

Crushed basalt was used as the coarse and fine aggregate to prepare AC-13 asphalt mixtures. Basalt is often selected as the aggregate of an asphalt mixture in upper pavements because of its high strength, durability, and good adhesion to bitumen. Aggregates passing percentages at sieve of sizes $16,9.5,4.75$, and $2.36 \mathrm{~mm}$ were $100 \%, 72 \%, 44 \%$, and $30 \%$, respectively. The average density of the used basalt aggregates was $2.983 \mathrm{~g} / \mathrm{cm}^{3}$, Los Angeles abrasion was $20.4 \%$, the polished stone value was 64 , and the crushed stone value was $19.5 \%$. The gradation curve is shown in Figure 1.

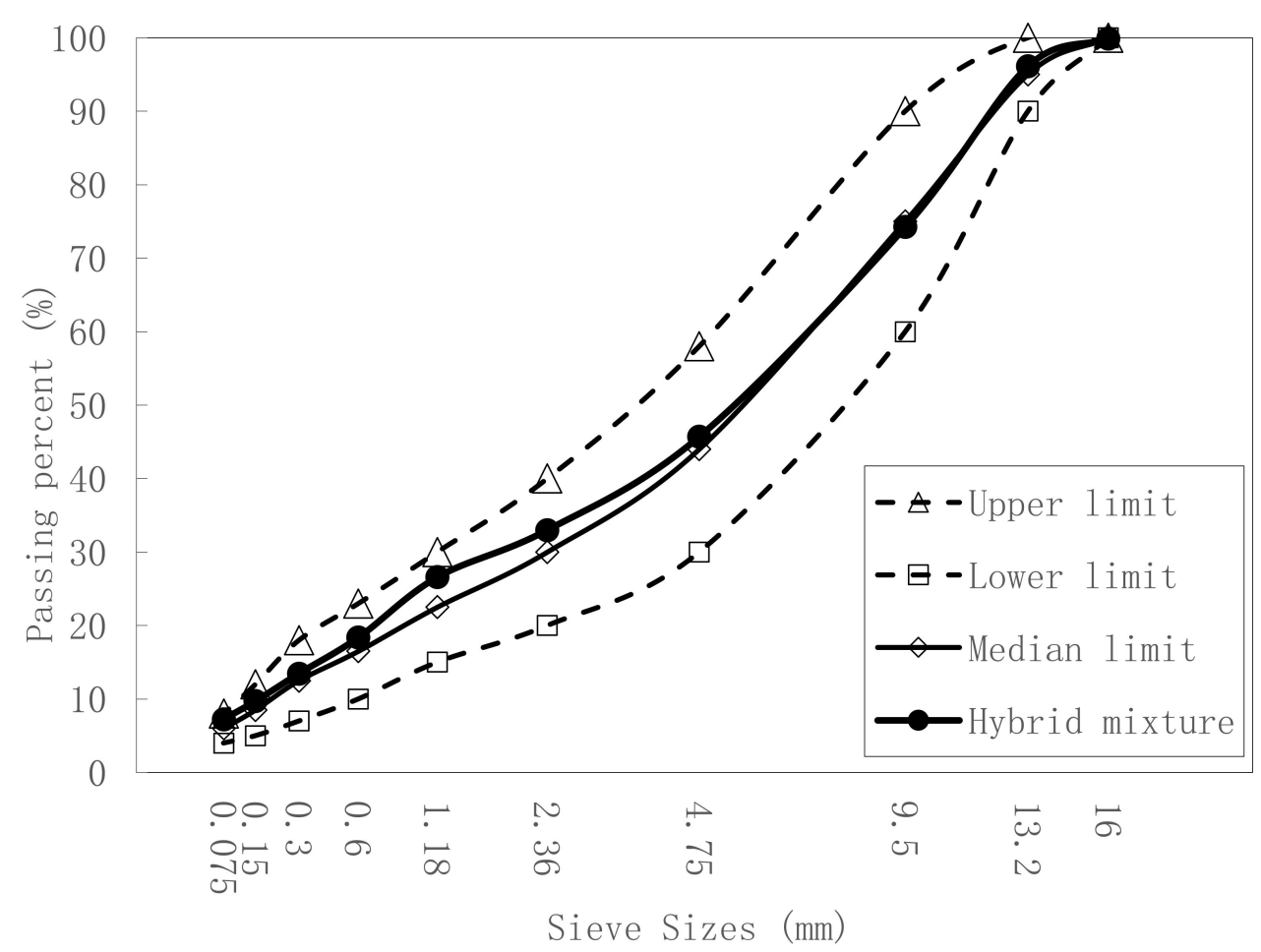

Figure 1. AC-13 gradation curve.

The physical properties of Styrene-butadiene-styrene block copolymer (SBS) asphalt binder were illustrated in Table 1. The asphalt mixture was prepared according to specification JTG E42-2005 [16]. The percentage of AC-13 asphalt mixture components were 4.4\% SBS bitumen, $26.8 \% 10-16 \mathrm{~mm}$ basalt, $26.8 \% 5-10 \mathrm{~mm}, 13.4 \% 3-5 \mathrm{~mm}, 24.8 \% 0-3 \mathrm{~mm}$, and $3.8 \%$ basalt powder filler. The air voids of the asphalt mixture was measured to be $4.5 \%$ when designing the mix proportion. The AC-13 asphalt mixtures were used for the upper layer of the pavement. 
Table 1. Physical properties of the SBS asphalt binder.

\begin{tabular}{|c|c|c|c|}
\hline \multicolumn{2}{|c|}{ Test Items } & Results & Requirements \\
\hline \multicolumn{2}{|c|}{ Penetration $25^{\circ} \mathrm{C}, 100 \mathrm{~g}, 5 \mathrm{~s}(0.1 \mathrm{~mm})$} & 76.2 & $60 \sim 80$ \\
\hline \multicolumn{2}{|c|}{ Softening point $\left({ }^{\circ} \mathrm{C}\right)$} & 63.6 & $\geq 60$ \\
\hline \multicolumn{2}{|c|}{ Ductility $5 \mathrm{~cm} / \mathrm{min}, 5^{\circ} \mathrm{C}(\mathrm{cm})$} & 51.2 & $\geq 30$ \\
\hline \multicolumn{2}{|c|}{ Density $15^{\circ} \mathrm{C}\left(\mathrm{g} / \mathrm{cm}^{3}\right)$} & 1.031 & / \\
\hline \multicolumn{2}{|c|}{ Solubility (TCE) (\%) } & 99.8 & $\geq 99$ \\
\hline \multirow{3}{*}{ Aging $163{ }^{\circ} \mathrm{C}, 5 \mathrm{~h}$} & Mass change (\%) & 0.4 & \pm 1.0 \\
\hline & Penetration ratio $25^{\circ} \mathrm{C}(\%)$ & 83.3 & $\geq 60$ \\
\hline & Residual ductility $5{ }^{\circ} \mathrm{C}(\mathrm{cm})$ & 32.3 & $\geq 20$ \\
\hline
\end{tabular}

The various loading tests were conducted in a multifunctional pavement material tester (MPT) developed by Wuhan University of Technology (Figure 2). Its functional part was a rubber wheel with a width of $40 \mathrm{~mm}$ that moved on two steel rails. The contact area was $1200 \mathrm{~mm}^{2}$. The load and speed of the flat rubber wheel was controlled by MPT to apply load on specimens, ranging from 0 to $30 \mathrm{MPa}$. The temperature inside was controlled by heating tubes and a water cooling circulation. Furthermore, there were additional modules that controlled UV, oxygen concentration, humidity, etc.

Aggregates and SBS bitumen were preheated to $165^{\circ} \mathrm{C}$ and compacted by a steel roller. To fully simulate the pavement service environment [17,18], large-sized specimens with a length of $1000 \mathrm{~mm}$, a width of $500 \mathrm{~mm}$, and a height of $40 \mathrm{~mm}$ were used in MPT (Figure 3). The finished specimens were left in room temperature for $24 \mathrm{~h}$ and conditioned in MPT for at least $6 \mathrm{~h}$ before test. The tests were carried out at $60^{\circ} \mathrm{C}$ and $40 \%$ humidity, and the wheel speed was 12 cycle/min $[16,19,20]$.


Figure 2. Multifunctional pavement material tester and its internal structure.

For each specimen, 10 aged core samples were extracted after 12 h, 36 h, 60 h, 84 h, and $108 \mathrm{~h}$. The tested specimen was cooled to $15^{\circ} \mathrm{C}$ in MPT. Then, the core samples were extracted by a core drilling machine. Two samples were taken at each time point for error reduction. The core sample was a cylinder with a diameter of $100 \mathrm{~mm}$ and a height of $40 \mathrm{~mm}$. The specimens were refilled to make up the holes with the same asphalt mixture after drilling so that the next tests could proceed smoothly. Next, the specimen was heated to $60^{\circ} \mathrm{C}$ for $6 \mathrm{~h}$ in MPT for subsequent tests. The permanent deformation of each sample was measured by a displacement sensor. Then, the unaffected part of the core sample was cut off to prepare the samples for other tests.

The measurement of TD and BPN of samples was conducted with the sand patch method and British pendulum according to specification JTG E42-2005 [16]. Before testing the BPN, samples were conditioned in $20^{\circ} \mathrm{C}$ and moistened by water. After the BPN and TD tests, samples were dissolved by 
toluene to separate aggregates from the asphalt binder. Then, the aggregates was sieved to observe the variation of aggregates after heavy load.

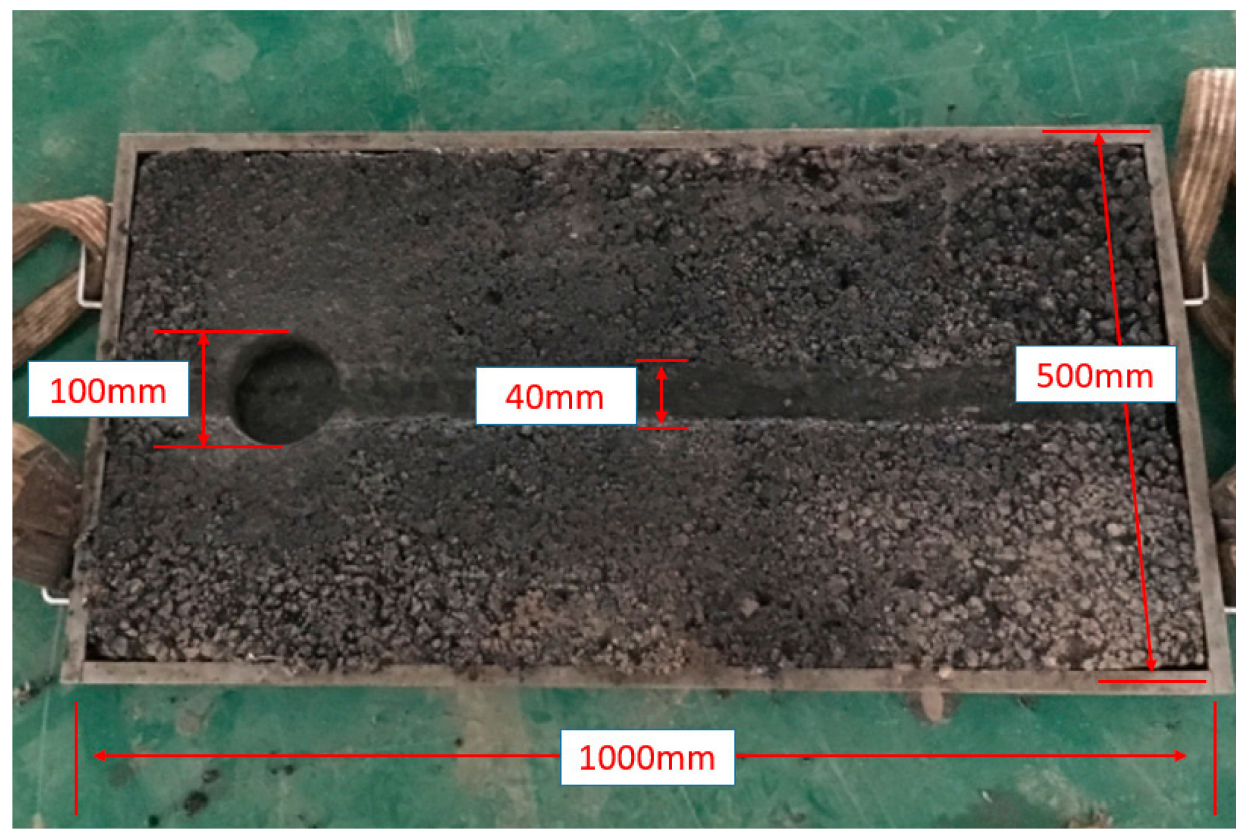

Figure 3. Specimen size and the core drilling.

The heavy load testing program for the upper layer of pavement of the AC-13 basalt asphalt mixture is shown in Table 2. The load was determined from a survey report of Chinese highway transportation to simulate the load that the overloaded truck brought to the asphalt pavement. A pressure of $0.7 \mathrm{MPa}$ was selected to represent normal wheel load and $0.9 \mathrm{MPa}, 1.1 \mathrm{MPa}$, and $1.4 \mathrm{MPa}$ were selected to simulate the overload environment [1]. Each load corresponded to a series number, and each sample's label indicated its load and duration.

Table 2. Heavy load testing program for the AC-13 basalt asphalt mixture.

\begin{tabular}{|c|c|c|c|c|}
\hline Series & Load/MPa & Specimen Label & Duration/h & Cumulative Cycles \\
\hline \multirow{5}{*}{$\mathrm{A}$} & \multirow{5}{*}{0.7} & AC-13-0.7-1 & 12 & 8640 \\
\hline & & AC-13-0.7-2 & 36 & 25,920 \\
\hline & & AC-13-0.7-3 & 60 & 43,200 \\
\hline & & AC-13-0.7-4 & 84 & 60,480 \\
\hline & & AC-13-0.7-5 & 108 & 77,760 \\
\hline \multirow{5}{*}{ B } & \multirow{5}{*}{0.9} & AC-13-0.9-1 & 12 & 8640 \\
\hline & & AC-13-0.9-2 & 36 & 25,920 \\
\hline & & AC-13-0.9-3 & 60 & 43,200 \\
\hline & & AC-13-0.9-4 & 84 & 60,480 \\
\hline & & AC-13-0.9-5 & 108 & 77,760 \\
\hline \multirow{5}{*}{$\mathrm{C}$} & \multirow{5}{*}{1.1} & AC-13-1.1-1 & 12 & 8640 \\
\hline & & AC-13-1.1-2 & 36 & 25,920 \\
\hline & & AC-13-1.1-3 & 60 & 43,200 \\
\hline & & AC-13-1.1-4 & 84 & 60,480 \\
\hline & & AC-13-1.1-5 & 108 & 77,760 \\
\hline \multirow{5}{*}{$\mathrm{D}$} & \multirow{5}{*}{1.4} & AC-13-1.4-1 & 12 & 8640 \\
\hline & & AC-13-1.4-2 & 36 & 25,920 \\
\hline & & AC-13-1.4-3 & 60 & 43,200 \\
\hline & & AC-13-1.4-4 & 84 & 60,480 \\
\hline & & AC-13-1.4-5 & 108 & 77,760 \\
\hline
\end{tabular}


The time-temperature superposition and thermo-rheological simplicity principles belong to the basic assumptions in the linear viscoelastic analysis [21,22]. Therefore, it is commonly used in the analysis of asphalt mixtures [23]. The WLF (Williams-Landel-Ferry) equation (Equation (1)) is defined using substantial experimental data based on the free volume theory by Williams, Landel, and Ferry [24].

$$
\lg \alpha_{\mathrm{T}}=\frac{-\mathrm{C}_{1}\left(\mathrm{~T}-\mathrm{T}_{0}\right)}{\mathrm{C}_{2}+\left(\mathrm{T}-\mathrm{T}_{0}\right)}
$$

where $C_{1}$ and $C_{2}$ are constants of the corresponding materials; $T$ is the shift temperature; $T_{0}$ is the reference temperature; $\lg \alpha_{\mathrm{T}}=\operatorname{lgt} \mathrm{t}_{0}-\operatorname{lgt}$; and $\mathrm{t}_{0}$ and $\mathrm{t}$ are the corresponding times of $\mathrm{T}_{0}$ and $\mathrm{T}$.

Equation (1) can be used to determine the corresponding time in real conditions by plugging in the constants $C_{1}$ and $C_{2}$ of the asphalt mixture [25] and the average temperature in central China. For the asphalt mixture, $C_{1}$ and $C_{2}$ were 38.46 and 316.35 , respectively. $T_{0}$ took the average annual road surface temperature of $327.75 \mathrm{~K}\left(54.6^{\circ} \mathrm{C}\right)$ in central China (Wuhan). $\mathrm{T}$ took the test temperature of $333.15 \mathrm{~K}$ $\left(60^{\circ} \mathrm{C}\right)$ in MPT. It was calculated that one day in the MPT equaled 4.65 days in real conditions. It was assumed that the width of the tire was $215 \mathrm{~mm}$, the flat ratio was $70 \%$, and speed was $90 \mathrm{~km} / \mathrm{h}$. It could be calculated that the average contact time between the tires and ground was $0.006 \mathrm{~s}$. According to JTG D50-2006, the traffic volume of a heavy load road was more than 1500 times per day with medium and large trucks and buses [26]. The vehicle model adopted a double rectangular uniformly distributed load. The coefficient of lanes was 0.45 . It could be calculated that the contact time per day was $16.1 \mathrm{~s}$. According to the parameter settings in MPT, the contact time between the tire and specimen in MPT could convert to $502.6 \mathrm{~s} / \mathrm{h}$ in real conditions. Therefore, $1 \mathrm{~h}$ in MPT could simulate 31 days in real conditions. This experiment could simulate the pavement condition of up to nine years in real conditions.

\section{Experimental Results and Discussion}

\subsection{Permanent Deformation Results}

Figure 4 shows the effects of various heavy loads on the development of rutting of the AC-13 pavement asphalt mixture. Four series were selected to represent different load levels and each series was constituted by five periods of cumulative cycles.

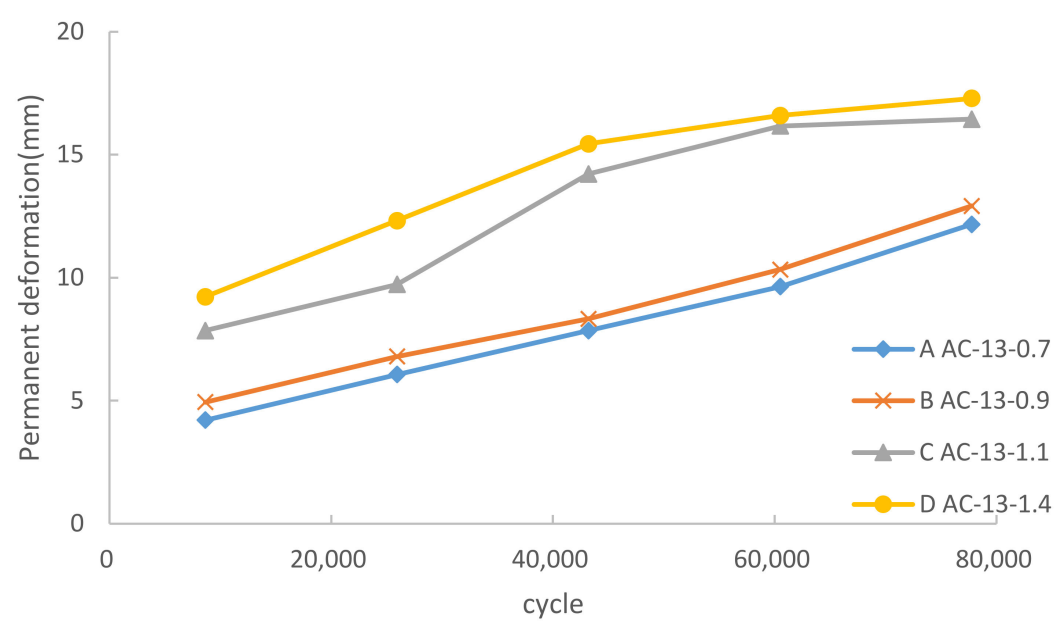

Figure 4. Heavy load effect on permanent deformation.

Normally, the development of permanent deformation of an asphalt mixture is divided into three stages: (1) Initial stage: the permanent deformation increases rapidly, but the growth rate decreases gradually; (2) Steady stage: the permanent deformation increases steadily, and the growth rate remains the same; and (3) Destroy stage: the permanent deformation and the growth increase rapidly until failure [27]. 
As shown in Figure 4, C and D revealed two distinct rutting stages while A and B rose steadily. The permanent deformation of $C$ and D could be divided into two stages: the initial stage (before 43,000 cycles) and the steady stage (43,000-80,000 cycles). However, the destroy stage was not observed. This indicated that the asphalt mixture would not go into the destroy stage in the service of nine years. The permanent deformation rose sharply in the initial stage and then became almost constant in the steady stage. The analysis of experimental data showed that $90 \%$ permanent deformation had been accomplished in the initial stage for lines $C$ and D. For lines A and B, the increase of permanent deformation was gentle and without obvious stage. The final value of $A$ and $B$ was $75 \%$ of $D$, equal to D with 26,000 cycles.

According to JTJ073.2-2001 [28], the allowable value of deformation is $15 \mathrm{~mm}$ in highways. Once the deformation exceeded $15 \mathrm{~mm}$, the pavement took the risk of failure and needed major repair. This indicates that pavements under normal load or slight overload will not run over the allowable value in the service of nine years. However, the pavement under heavy load would exceed the allowable deformation within 45,000 cycles.

The wheel tracking slope (WTS) can be used to describe the increase in permanent deformation [29]: WTS $=\left(\mathrm{h}_{\text {cycle } 1}-\mathrm{h}_{\text {cycle2 }}\right) /($ cycle1-cycle2 $)$, where $\mathrm{h}_{\text {cycle }}$ is the depth of deformation in the cycle. According to the data, after 60,000 cycles of the tests, the WTS of A, B, C, D were calculated as $0.89 \mathrm{~mm} /\left(10^{4}\right.$ cycles $)$, $0.92 \mathrm{~mm} /\left(10^{4}\right.$ cycles $), 0.15 \mathrm{~mm} /\left(10^{4}\right.$ cycles $)$, and $0.40 \mathrm{~mm} /\left(10^{4}\right.$ cycles $)$, respectively. The WTS of A and B were much higher than $\mathrm{C}$ and $\mathrm{D}$. This illustrates that the growth of deformation had slowed down in $\mathrm{C}$ and D, but remained stable in A and B. Therefore, the structure of C and D went into a stable state, while the structure of A and B were still changing.

The above results indicate that there was a steady growth in the permanent deformation of the asphalt pavement under some critical pressure value. According to the results of this experiment, this critical load value was nearly 1.0 MPa, depending on the performance of the aggregates used. Once the vehicle load was beyond the critical load value, the permanent deformation of the asphalt pavement was going to develop rapidly to reach the majority of the final value. Then, the following development of permanent deformation could be very slow-growing. The destruction of stable structure under high load in the initial stage led to the sharp increase in deformation. As shown in Figure 5, the aggregates were crushed into pieces and reformed a new stable structure. Once the new stable structure took shape, the rapid increase in permanent deformation would slow down.

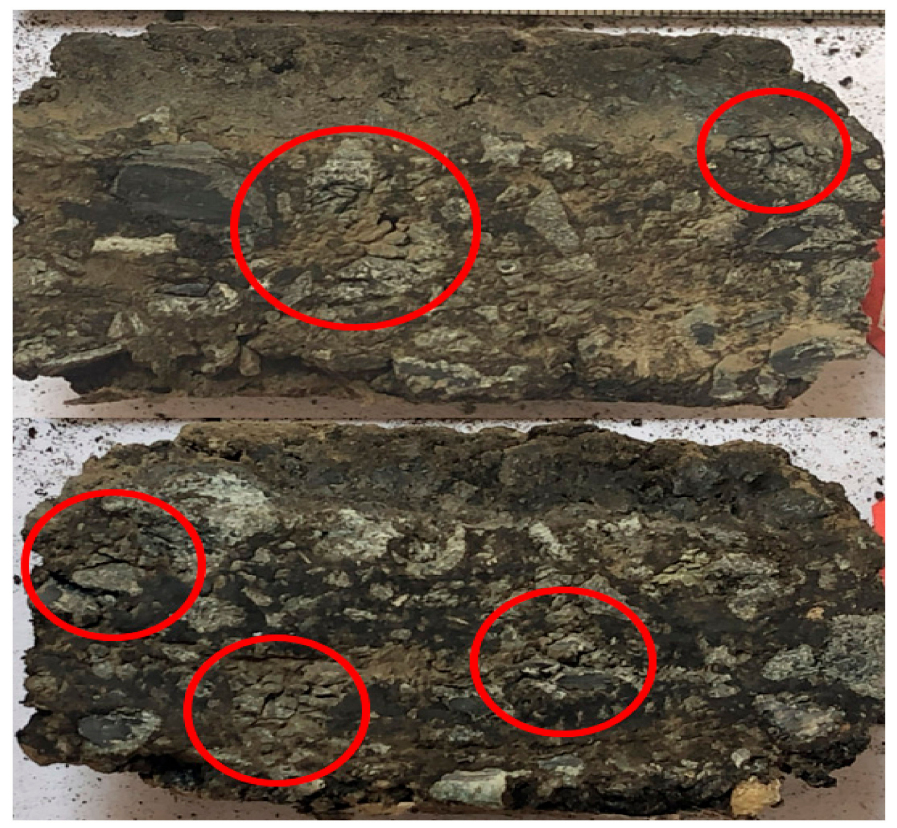

Figure 5. Broken part in the cross-section view of the samples. 


\subsection{Skid Resistance Results}

Figures 6 and 7 show the variation in the skid resistance of the asphalt pavement under heavy load. The initial BPN and TD of samples were 75.5 and $1.873 \mathrm{~mm}$, respectively.

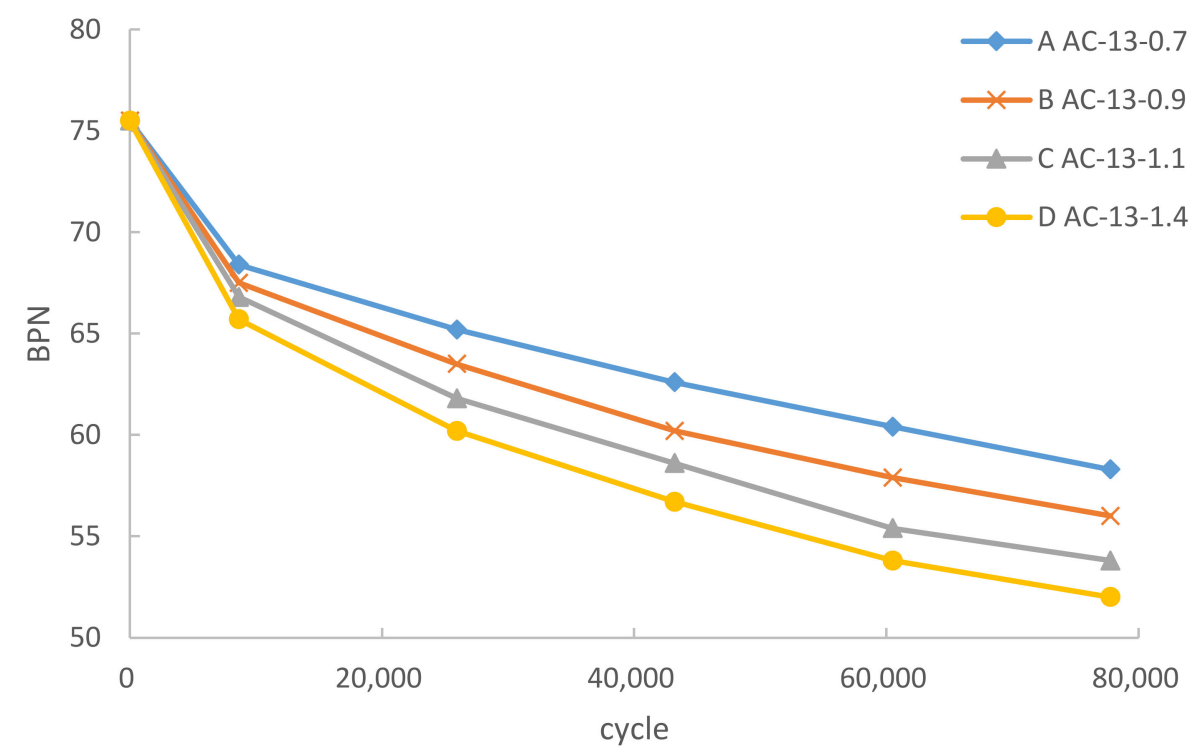

Figure 6. Heavy load effect on the British pendulum number.

As shown in Figure 6, the BPN of the asphalt mixture under various load decreased with the increase in cumulative cycles. At the beginning of the test, BPN decreased rapidly and stabilized gradually with the increase of cumulative cycles. The final BPN dropped by $23 \%-31 \%$ to a varying degree. With the increase in wheel load, the decline in the mixture became faster and the abrasion of aggregates became more severe. The mixture under 1.4 MPa had the maximum degradation range and the minimum final value.

It was found that after 4000 5000 times of wheel grinding, the asphalt mixture on the surface was compacted to expose the edges of the inner aggregates because of densification. After that, the aggregate corners and edges without mixture protection were gradually destroyed by the wheel. The skid resistance began to decline rapidly after this point. The mixture under 1.4 MPa was worn severely under the wheel load. There were obviously crushed aggregates and bleeding on the surface of the mixture under 1.1 MPa and 1.4 MPa. There were no obviously crushed aggregates on the surface of the mixture under $0.7 \mathrm{MPa}$ and $0.9 \mathrm{MPa}$, but bleeding was observed to different degrees.

According to JTJ073.2-2001 [28], the allowable BPN of highway should be higher than 45 . The fitting curve for BPN to the cumulative cycles under 0.7 MPa was plotted with the model of power function by software Statistical Product and Service Solutions (SPSS). According to the fitting curve, the approximate cumulative cycles under $0.7 \mathrm{MPa}$ required to degrade the BPN to 45 was estimated to be 4.09 million. The cumulative cycles under $0.9 \mathrm{MPa}, 1.1 \mathrm{MPa}$, and 1.4 MPa could be estimated as 1.26 million, 0.55 million, and 0.34 million, respectively with the similar approach. The simulated results showed that skid resistance could be maintained for a long time under normal load. However, with the increase in wheel load, the skid resistance disappeared quickly.

As shown in Figure 7, the change rule of TD was similar to the BPN. In the initial stage of heavy wheel load, the asphalt mixture was compacted to expose the corners and edges of aggregates on the surface. The destruction of the surface structure led to the quick decline of TD. Then the corners of aggregates were ground off and the aggregates was crushed into pieces by heavy load gradually, leading to further decline of TD in the later stage. Eventually, the decrease of TD tended to balance with the polishing of the mixture surface. Overall, TD decreased by $40-60 \%$ with various wheel loads, where the higher load made the faster decline and the lower final value of TD. 




Figure 7. Heavy load effect on TD.

According to JTG D50-2006 [26], the allowable TD for an asphalt mixture should be higher than $0.55 \mathrm{~mm}$. The same analytical method as BPN was adopted to estimate the maximum cumulative cycles of $0.7 \mathrm{MPa}, 0.9 \mathrm{MPa}, 1.1 \mathrm{MPa}$, and $1.4 \mathrm{MPa}$ were 0.88 million, 0.39 million, 0.23 million, and 0.12 million, respectively. This simulation illustrates that the TD of the asphalt mixture failed faster than BPN. The maximum cumulative cycles under heavy load would be reduced by more than $80 \%$, and a heavy load condition would greatly speed up the failure in skid resistance.

\subsection{Sieving Results}

The sieving results of the ground mixture are shown in Table 3. Due to the loss of fine aggregates and mineral powder filler during dissolution and filtration, the percentage of $0-3 \mathrm{~mm}$ parts was compensated by $3 \%$.

Table 3. Sieving result of ground asphalt mixture.

\begin{tabular}{ccccc}
\hline Specimen Label & $\mathbf{1 0 - 1 6} \mathbf{~ m m}$ & $\mathbf{5 - 1 0} \mathbf{~ m m}$ & $\mathbf{3 - 5} \mathbf{~} \mathbf{m}$ & $\mathbf{0 - 3} \mathbf{~ m m}$ and Filler \\
\hline AC-13 & $28 \%$ & $\mathbf{2 8} \%$ & $14 \%$ & $30 \%$ \\
AC-13-0.7-1 & $24.18 \%$ & $30.95 \%$ & $16.11 \%$ & $28.75 \%$ \\
AC-13-0.7-2 & $22.16 \%$ & $30.51 \%$ & $17.57 \%$ & $29.76 \%$ \\
AC-13-0.7-3 & $21.42 \%$ & $31.65 \%$ & $17.95 \%$ & $28.98 \%$ \\
AC-13-0.7-4 & $20.09 \%$ & $32.86 \%$ & $17.71 \%$ & $29.34 \%$ \\
AC-13-0.7-5 & $15.82 \%$ & $34.80 \%$ & $19.67 \%$ & $29.71 \%$ \\
AC-13-0.9-1 & $22.80 \%$ & $31.57 \%$ & $17.46 \%$ & $28.17 \%$ \\
AC-13-0.9-2 & $21.77 \%$ & $31.46 \%$ & $17.32 \%$ & $29.45 \%$ \\
AC-13-0.9-3 & $20.86 \%$ & $32.34 \%$ & $18.16 \%$ & $28.64 \%$ \\
AC-13-0.9-4 & $18.82 \%$ & $33.48 \%$ & $18.76 \%$ & $28.94 \%$ \\
AC-13-0.9-5 & $14.66 \%$ & $35.46 \%$ & $20.45 \%$ & $29.43 \%$ \\
AC-13-1.1-1 & $20.68 \%$ & $32.26 \%$ & $18.75 \%$ & $28.31 \%$ \\
AC-13-1.1-2 & $20.28 \%$ & $33.38 \%$ & $18.51 \%$ & $27.83 \%$ \\
AC-13-1.1-3 & $16.97 \%$ & $34.27 \%$ & $20.73 \%$ & $28.03 \%$ \\
AC-13-1.1-4 & $13.29 \%$ & $35.30 \%$ & $22.63 \%$ & $28.78 \%$ \\
AC-13-1.1-5 & $10.05 \%$ & $37.76 \%$ & $23.53 \%$ & $28.65 \%$ \\
AC-13-1.4-1 & $19.38 \%$ & $33.34 \%$ & $19.51 \%$ & $27.77 \%$ \\
AC-13-1.4-2 & $17.62 \%$ & $33.65 \%$ & $19.85 \%$ & $28.89 \%$ \\
AC-13-1.4-3 & $15.01 \%$ & $34.26 \%$ & $22.87 \%$ & $27.86 \%$ \\
AC-13-1.4-4 & $12.61 \%$ & $36.22 \%$ & $23.02 \%$ & $28.16 \%$ \\
AC-13-1.4-5 & $10.17 \%$ & $36.40 \%$ & $23.37 \%$ & $30.06 \%$ \\
\hline & & & & \\
\hline
\end{tabular}


As shown in Table 3, the 0-3 mm and filler part of the aggregates changed insignificantly in the grinding process. Considering the loss in separation, it may be that the $0-3 \mathrm{~mm}$ and filler part had no loss or increase in the whole process. The content of 10-16 mm decreased continuously, while the content of 5-10 $\mathrm{mm}$ and 3-5 mm increased with the progress of the tests. Figure 8 showed the change of the other parts in the grinding process. The Y-axis in Figure 8 represents the percentage of the aggregate in the ground asphalt mixture. Figure $8 \mathrm{~A}$ shows the $10-16 \mathrm{~mm}$ loss, and $\mathrm{B}$ and $\mathrm{C}$ show the rise in 5-10 $\mathrm{mm}$ and $3-5 \mathrm{~mm}$, respectively.



A

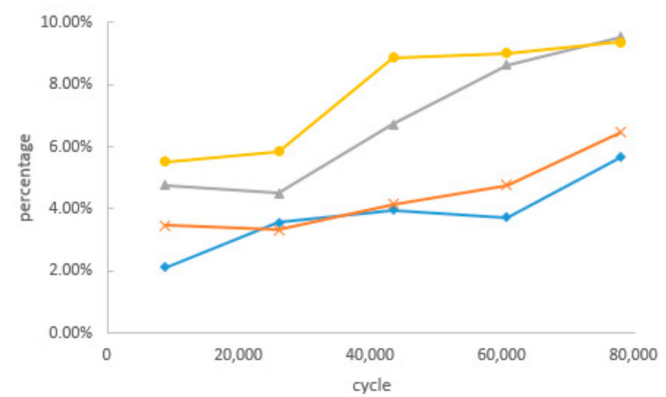

$\mathrm{C}$



B

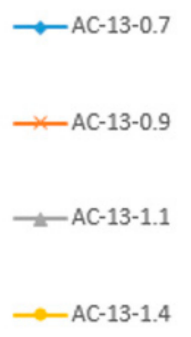

$-\mathrm{AC}-13-1.4$

Figure 8. Gradation change in the ground mixture. (A) The loss in 10-16 mm, (B) the rise in 5-10 mm, (C) the rise in 3-5 $\mathrm{mm}$.

As shown in Figure 8A, the 10-16 mm part was greatly affected by the load and cumulative cycles. In the whole process, the loss of $10-16 \mathrm{~mm}$ was more than $15 \%$ of the total. The decline of the $10-16 \mathrm{~mm}$ was slow under lower loads (0.7 MPa and $0.9 \mathrm{MPa})$, while the decline under a higher load (1.1 MPa and 1.4 MPa) was faster. Relatively, the changes in the 5-10 mm and 3-5 mm parts were less than 10-16 mm, owing to both additions crushed from the upper aggregates and loss crushed into smaller pieces. Furthermore, the rise in 5-10 $\mathrm{mm}$ roughly equaled the rise in 3-5 $\mathrm{mm}$. Overall, the loss of $10-16 \mathrm{~mm}$ approximately equaled the rise of the $5-10 \mathrm{~mm}$ and $3-5 \mathrm{~mm}$. Ignoring the repeated increase or decrease, it could be considered that the effect of heavy load on the AC-13 asphalt mixture was to divide the $10-16 \mathrm{~mm}$ part half into $5-10 \mathrm{~mm}$, and the other half into $3-5 \mathrm{~mm}$.

The curve under the higher load presented two stages, the same as the curve of permanent deformation under high load. It illustrated that the deformation of the pavement under high load was related to the change in the aggregate gradation. According to Table 3, mixtures under 1.1 MPa and 1.4 MPa had similar final aggregate gradations after a long period of grinding. The new aggregate gradation of $10-16 \mathrm{~mm}, 5-10 \mathrm{~mm}, 3-5 \mathrm{~mm}$, and 0-3 mm was approximately $10 \%, 37 \%, 23 \%$, and $30 \%$, respectively. This suggests that $\mathrm{C}$ and $\mathrm{D}$ formed a similar stable skeleton structure, while the skeleton structures of A and B were still changing. This result was consistent with the conclusion of permanent deformation. This demonstrates that the aggregates would be crushed into smaller pieces and reform a stable structure after high load grinding.

The gradation curve after heavy load grinding is shown in Figure 9. Although the hybrid mixture curve was close to the upper limit, it was still between the upper and lower limit. 




Figure 9. Gradation curve after heavy load.

\subsection{Correlation Analysis}

To investigate the cause of the performance change of the asphalt mixture, correlation analysis between the content of different aggregates and mixture performance was conducted by SPSS. The Pearson correlation coefficient (PCC) and the significance level (Sig.) are computed and listed in Table 4. The PCC is a measure of the linear correlation between two variables, $\mathrm{X}$ and $\mathrm{Y}$. The PCC has a value between 1 and -1 , where 1 is total positive correlation, 0 is no correlation, and -1 is total negative correlation. The PCC can be computed by Equation (2) [30].

$$
r_{x y}=\frac{\sum_{i=1}^{n}\left(x_{i}-\bar{x}\right)\left(y_{i}-\bar{y}\right)}{\sqrt{\sum_{i=1}^{n}(x i-\bar{x})^{2}} \sqrt{\sum_{i=1}^{n}(y i-\bar{y})^{2}}}
$$

where $\mathrm{n}$ is sample size; $\mathrm{x}_{\mathrm{i}}, \mathrm{y}_{\mathrm{i}}$ are the individual sample; $\overline{\mathrm{x}}=\frac{1}{\mathrm{n}} \sum_{\mathrm{i}=1}^{\mathrm{n}} \mathrm{x}_{\mathrm{i}}$, analogously for $\bar{y}$.

As shown in Table 4, for aggregates in the three sizes of $10-16 \mathrm{~mm}, 5-10 \mathrm{~mm}$, and 3-5 mm, the correlation between $10-16 \mathrm{~mm}$ and mixture performance was the highest, followed by $3-5 \mathrm{~mm}$ and 5-10 $\mathrm{mm}$. Permanent deformation had the highest correlation with aggregates among the three performance indexes. All the aggregates could pass the 0.05 significance test on permanent deformation. That indicated there were relationships between aggregate gradation and permanent deformation. Furthermore, the $10-16 \mathrm{~mm}$ aggregate could pass the 0.01 significance test on deformation. This indicates that the 10-16 $\mathrm{mm}$ aggregate had the most significant correlation with permanent deformation. This implies that the content of $10-16 \mathrm{~mm}$ in pavements could be used to measure its performance. However, TD had the lowest correlation with aggregates and most of them failed the 0.05 significance test. Relevant data showed that TD and BPN had a good correlation, and the correlation coefficient under various loads was above 0.97 . This indicates that there was no significant relationship between the skid resistance of the asphalt mixture and the aggregate gradation, but there was a significant relationship between BPN and TD. This illustrates that the rutting performance was related to the aggregate and its gradation, while the skid resistance was related to the shapes, edges, and corners of the aggregate on the surface.

With the increase in load, the correlation between permanent deformation and aggregates gradually decreased. This indicates that the permanent deformation had a higher correlation with aggregates under low load. 
Table 4. Correlation between gradation and mixture performance.

\begin{tabular}{cccccccc}
\hline \multirow{2}{*}{ Load/MPa } & \multirow{2}{*}{ Aggregate/mm } & \multicolumn{2}{c}{ Permanent Deformation } & \multicolumn{2}{c}{ BPN } & \multicolumn{3}{c}{ TD } \\
\cline { 3 - 8 } & & PCC & Sig. & PCC & Sig. & PCC & Sig. \\
\hline \multirow{3}{*}{0.70} & $10-16$ & 0.972 & 0.006 & -0.934 & 0.200 & -0.857 & 0.063 \\
& $5-10$ & 0.938 & 0.018 & -0.883 & 0.047 & -0.762 & 0.134 \\
& $3-5$ & 0.923 & 0.025 & -0.906 & 0.034 & -0.877 & 0.051 \\
\hline \multirow{3}{*}{0.90} & $10-16$ & 0.972 & 0.006 & -0.889 & 0.044 & -0.826 & 0.085 \\
& $5-10$ & 0.957 & 0.011 & -0.868 & 0.056 & -0.794 & 0.109 \\
& $3-5$ & 0.950 & 0.013 & -0.861 & 0.061 & -0.783 & 0.117 \\
\hline \multirow{3}{*}{1.10} & $10-16$ & 0.926 & 0.024 & -0.929 & 0.023 & -0.896 & 0.040 \\
& $5-10$ & 0.882 & 0.048 & -0.928 & 0.023 & -0.892 & 0.042 \\
& $3-5$ & 0.948 & 0.014 & -0.922 & 0.026 & -0.897 & 0.039 \\
& $10-16$ & 0.950 & 0.013 & -0.969 & 0.007 & -0.916 & 0.029 \\
& $5-10$ & 0.882 & 0.048 & -0.912 & 0.031 & -0.845 & 0.072 \\
& $3-5$ & 0.957 & 0.011 & -0.927 & 0.023 & -0.901 & 0.037 \\
\hline
\end{tabular}

\section{Conclusions}

Large-sized specimen wheel tracking testing on AC-13 basalt asphalt mixtures was carried out to study the development of the mixture under heavy load condition. The changing rules of deformation and skid resistance were consistent with the results of standard tests $[1,6]$. The following results were obtained:

(1) In the service of nine years, the permanent deformation of the asphalt mixture increased slowly under low load, while developed by obvious stages under high load: increased rapidly at the initial stage, and then slowed down. The deformation growth speed of the asphalt mixture under high load would decrease due to the formation of a new stable structure after 60,000 cycles. There was a critical load between the two development models, which was related to the performance of the aggregates.

(2) The asphalt mixture on the surface had been compacted, exposing the corners and edges of the aggregates after grinding approximately 5000 times. The skid resistance began to decline rapidly after this point. BPN and TD had a larger degradation range and smaller final value under higher load.

(3) In terms of permanent deformation, the asphalt mixture remained effective for a long time under low load, while it failed after grinding 45,000 times under high load. The failure cumulative cycles of skid resistance under various loads was predicted by the fitting curve. The failure cumulative cycles on BPN under 0.7 MPa, 0.9 MPa, 1.1 MPa, and 1.4 MPa was 4.09 million, 1.26 million, 0.55 million, and 0.34 million, respectively. The failure cumulative cycles on TD under $0.7 \mathrm{MPa}$, $0.9 \mathrm{MPa}, 1.1 \mathrm{MPa}$, and $1.4 \mathrm{MPa}$ was 0.88 million, 0.39 million, 0.23 million, and 0.12 million, respectively. The failure on TD was faster than BPN.

(4) According to the sieving result of the ground samples under heavy load, it was found that the content of 0-3 mm was almost constant, $10-16 \mathrm{~mm}$ decreased, while 5-10 $\mathrm{mm}$ and 3-5 $\mathrm{mm}$ rose. It could be viewed as some of the 10-16 mm particles were crushed into $5-10 \mathrm{~mm}$ and $3-5 \mathrm{~mm}$.

(5) Aggregates were crushed into smaller pieces and reformed a stable structure after high load grinding. The new aggregate gradation of $10-16 \mathrm{~mm}, 5-10 \mathrm{~mm}, 3-5 \mathrm{~mm}$, and $0-3 \mathrm{~mm}$ was approximately $10 \%, 37 \%, 23 \%$, and $30 \%$, respectively.

(6) According to the correlation analysis, the content of $10-16 \mathrm{~mm}$ had a significant correlation with the rutting performance of the mixture. There was no significant relationship between the aggregate gradation and skid resistance of the asphalt mixture. With the increase in the load, the correlation between permanent deformation and the aggregates gradually decreased. 
Author Contributions: Conceptualization, J.L.; Data curation, J.L., Q.Y.; Formal analysis, J.L., J.X.; Methodology, J.L., J.X.; Supervision, J.Y.; Investigation, J.X.; Resources, Q.Y.; Writing-original draft, J.L.; Writing-review\&editing, J.L.

Funding: This research was funded by the National Natural Science Foundation of China, grant number 71961137010; the National Natural Science Foundation of China, grant number 51708437; the Major Science and Technology Projects of Inner Mongolia Autonomous Region, grant number zdzx2018029; the Open Fund of Key Laboratory of Road Structure and Material of Ministry of Transport (Changsha University of Science \& Technology), grant number kfj180301. And the APC was funded by National Natural Science Foundation of China.

Conflicts of Interest: The authors declare no conflict of interest.

\section{References}

1. Javilla, B.; Mo, L.; Hao, F.; Shu, B.; Wu, S. Multi-stress loading effect on rutting performance of asphalt mixtures based on wheel tracking testing. Constr. Build. Mater. 2017, 148, 1-9. [CrossRef]

2. Miao, Y.; Li, J.; Zheng, X.; Wang, L. Field investigation of skid resistance degradation of asphalt pavement during early service. Int. J. Pavement Res. Technol. 2016, 9, 313-320. [CrossRef]

3. Karakaş, A.S.; Sayin, B.; Kuloğlu, N. The changes in the mechanical properties of neat and SBS-modified HMA pavements due to traffic loads and environmental effects over a one-year period. Constr. Build. Mater. 2014, 71, 406-415. [CrossRef]

4. Li, Q.; Yang, H.; Ni, F.; Ma, X.; Luo, L. Cause analysis on permanent deformation for asphalt pavements using field cores. Constr. Build. Mater. 2015, 100, 40-51. [CrossRef]

5. Zhang, Q.; Chen, Y.; Li, X. Rutting in asphalt pavement under heavy load and high temperature. In Proceedings of the Asphalt Material Characterization, Accelerated Testing, and Highway Management, GeoHunan International Conference, Hunan, China, 15 September 2009; pp. 39-48.

6. Rezaei, A.; Masad, E.; Chowdhury, A.; Harris, P. Predicting asphalt mixture skid resistance by aggregate characteristics and gradation. Transp. Res. Rec. 2009, 2104, 24-33. [CrossRef]

7. Mataei, B.; Zakeri, H.; Zahedi, M.; Nejad, F.M. Pavement friction and skid resistance measurement methods: A literature review. Open J. Civ. Eng. 2016, 6, 537-565. [CrossRef]

8. Gao, L.; Liu, M.; Wang, Z.; Xie, J.; Jia, S. Correction of texture depth of porous asphalt pavement based on CT scanning technique. Constr. Build. Mater. 2019, 200, 514-520. [CrossRef]

9. Ahadi, M.R.; Nasirahmadi, K. The effect of asphalt concrete micro \& macro texture on skid resistance. J. Rehabil. Civil Eng. 2013, 1, 15-28.

10. Luce, A.; Mahmoud, E.; Masad, E.; Chowdhury, A. Relationship of aggregate microtexture to asphalt pavement skid resistance. J. Test. Eval. 2007, 35, 578-588.

11. Walubita, L.F.; Zhang, J.; Das, G.; Hu, X.; Mushota, C.; Alvarez, A.E.; Scullion, T. Hot-mix asphalt permanent deformation evaluated by Hamburg wheel tracking, dynamic modulus, and repeated load tests. Transp. Res. Rec. 2012, 2296, 46-56. [CrossRef]

12. Zheng, M.L.; Zhu, H.T. Research progress on testing technology and evaluation model of skid-resistant performance of pavement. Highw. Trans. Res. Dev. 2008, 9, 313-314.

13. Praticò, F.G.; Vaiana, R. A study on the relationship between mean texture depth and mean profile depth of asphalt pavements. Constr. Build. Mater. 2015, 101, 72-79. [CrossRef]

14. Zhang, J.X.; Liu, L.H.; Wang, L.L. Influence of speed and texture depth on skid resistance of pavement surface. J. Beijing Univ. Technol. 2009, 35, 48-52.

15. Lin, C.; Tongjing, W. Effect of fine aggregate angularity on skid-resistance of asphalt pavement using accelerated pavement testing. Constr. Build. Mater. 2018, 168, 41-46. [CrossRef]

16. JTG E20-2011. Standard Test Methods of Bitumen and Bituminous Mixtures for Highway Engineering; Ministry of Transport: Beijing, China, 2011.

17. Korkiala-Tanttu, L.; Dawson, A. Relating full-scale pavement rutting to laboratory permanent deformation testing. Int. J. Pavement Eng. 2007, 8, 19-28. [CrossRef]

18. Gilchrist, M.D.; Hartman, A.M.; Owende, P.M.O.; Ward, S.M. Full scale accelerated testing of bituminous road pavement mixtures Key Engineering Materials. Trans. Tech. Publ. 2001, 204, 443-452.

19. Chen, X.; Huang, B.; Xu, Z. Comparison between flat rubber wheeled loaded wheel tester and asphalt pavement analyzer. Road Mater. Pavement Des. 2007, 8, 595-604. [CrossRef] 
20. Iskender, E.; Aksoy, A. Field and laboratory performance comparison for asphalt mixtures with different moisture conditioning systems. Constr. Build. Mater. 2012, 27, 45-53. [CrossRef]

21. Jaczewski, M.; Judycki, J.; Jaskula, P. Asphalt concrete subjected to long-time loading at low temperatures-Deviations from the time-temperature superposition principle. Constr. Build. Mater. 2019, 202, 426-439. [CrossRef]

22. Monismith, C.L.; Alexander, R.L.; Secor, K.E. Rheologic behavior of asphalt concrete. Assoc. Asphalt Paving Technol. Proc. 1966, 35, 400-450.

23. Kim, Y.R. Modeling of Asphalt Concrete. Am. Soc. Civ. Eng. 2009.

24. Ferry, J.D. Viscoelastic Properties of Polymers; John Wiley and Sons: Hoboken, NJ, USA, 1980.

25. Yin, Y.; Huang, W.; Lv, J.; Ma, X.; Yan, J. Unified construction of dynamic rheological master curve of asphalts and asphalt mixtures. Int. J. Civ. Eng. 2018, 16, 1057-1067. [CrossRef]

26. JTG D50-2006. Specifications for Design of Highway Asphalt Pavement; Ministry of Transport: Beijing, China, 2006.

27. Witczak, M.W. Simple Performance Test for Superpave Mix Design; Transportation Research Board: Washington, DC, USA, 2002.

28. JTJ073.2-2001. Technical Specification for Maintenance of Highway Asphalt Pavement; Ministry of Transport: Beijing, China, 2001.

29. Morea, F.; Zerbino, R. Wheel tracking test (WTT) conducted under different standards. Study and correlation of test parameters and limits. Mater. Struct. 2015, 48, 4019-4028. [CrossRef]

30. Sedgwick, P. Pearson's correlation coefficient. BMJ 2012, 345, e4483. [CrossRef]

(C) 2019 by the authors. Licensee MDPI, Basel, Switzerland. This article is an open access article distributed under the terms and conditions of the Creative Commons Attribution (CC BY) license (http://creativecommons.org/licenses/by/4.0/). 